ORIGINAL ARTICLE

\title{
Efficacy of prophylactic parenteral paracetamol to decrease rate of ductus patency in preterm infants.
}

\author{
Bushra Madni' ${ }^{1}$, Muhammad Imran², Muhammad Naveed ${ }^{3}$, Fazal ur Rehman ${ }^{4}$, Khurram Shahnawaz ${ }^{5}$, Farhan Zahoor ${ }^{6}$
}

Article Citation: Madni B, Imran M, Naveed M, Fazal ur Rehman, Shahnawaz K, Zahoor F. Efficacy of prophylactic parenteral paracetamol to decrease rate of ductus patency in preterm infants. Professional Med J 2022; 29(1):126-130. https://doi.org/10.29309/TPMJ/2022.29.01.6528

\begin{abstract}
Objective: To find out the effectiveness of prophylactic parenteral paracetamol to minimize rates of ductus patency among preterm infants. Study Design: Case-control study. Setting: Department of Pediatrics, Sughra Shafi Medical Complex, Sahara Medical College, Narowal, Pakistan. Period: March 2020 to February 2021. Material \& Methods: A total of 70 neonates ( 35 cases and 35 controls) having gestational age less than or equal to 34 weeks were enrolled. All 35 cases were administered prophylactic parenteral paracetamol as $20 \mathrm{mg}$ per $\mathrm{kg}$ stat and $7.5 \mathrm{mg}$ per $\mathrm{kg} 6$ hourly for $1^{\text {st }} 3$ days of life while all controls were given no drugs. Echocardiography was performed in all 70 neonates after $1^{\text {st }}$ three post-natal days to identify PDA. Data was analyzed using SPSS 26.0. Results: In a total of 70 neonates, 37 (52.9\%) were male and 33 $(47.1 \%)$ female. Overall, mean gestational age was noted to be $32.1+1.47$ weeks while mean body weight was recorded to be $1424.6+229.7$ grams. There were 6 neonates $(17.1 \%)$ among cases who were found to have PDA in comparison to $23(65.7 \%)$ in controls $(p<0.0001)$. Four $(11.4 \%)$ neonates died in case group in comparison to $7(20.0 \%)$ among controls $(p=0.3245)$. Mean duration of hospitalization was recorded to be $20.52+8.2$ days in case group in comparison to $24.81+4.6$ days among controls $(p=0.0088)$. Conclusion: Prophylactic parenteral paracetamol was found to prevent ductus patency among preterm neonates. In comparison to controls, duration of hospital stay was significantly short among neonates who were administered prophylactic parenteral paracetamol.
\end{abstract}

Key words: Ductus Patency, Paracetamol, Preterm.

\section{INTRODUCTION}

As fetal pulmonary vascular resistance is high, around $90 \%$ of the blood ejecting through the fetal right ventricle is flowing through ductus arteriosus (DA) to the descending aorta. ${ }^{1}$ The DA usually remains closed in the first few days following birth while the whole right ventricular output ejecting in the pulmonary arterial bed. In case if DA stays patent in the post-natal period and decrease is pulmonary vascular resistance occurs, blood flow through DA reverses from aorta to pulmonary artery. ${ }^{2}$ As this connection is open during systole and diastole and the pulmonary artery pressure is comparatively low to aortic pressure, blood flows from the patent ductus arteriosus (PDA) throughout the cardiac cycle. In consequence to this, the volume overload results in enlargement of the pulmonary artery and veins, left atrium as well as left ventricle. ${ }^{3}$

Indomethacin and ibuprofen are considered to the best choices for closing PDA and have shown effectiveness between 70-80\% except in cases where kidney failure, oligouria, distinct thrombocytopenia, active bleeding, necrotizing enterocolitis (NEC) and bowel perforation. , $^{4,5}$ In case of treatment failure of any possible contraindications to the treatment, surgical closure is opted. As paracetamol has been in use for controlling pain among neonates, some researchers have pointed towards it role in PDA closure with less side effects. ${ }^{6,7} A$ recent study from Iran reported frequency of PDA among neonates who were given prophylactic parenteral paracetamol to be $15 \%$ in comparison to $71.3 \%$ in controls. ${ }^{8}$ Some previous trials have exhibited
1. FCPS (Pediatric Medicine), Assistant Professor Pediatric Medicine, Shalamar Medical and Dental College Lahore.

2. FCPS (Pediatric Medicine), Assistant Professor Pediatric Medicine, Pir Abdul Qadir Shah Jillani Institute of Medical Sciences, Gambat.

3. FCPS (Pediatric Medicine), Senior Registrar Pediatrics, Sahara Medical College Narowal.

4. FCPS (Pediatric Medicine), Fellow Pediatric Cardiology, NICVD, Karachi.

5. FCPS (Pediatric Medicine), Associate Professor Pediatrics, Sahara Medical College Narowal.

6. FCPS (Pediatric Medicine), Assistant Professor Pediatrics, Fatima Jinnah Medical University/Sir Gangaram Hospital, Lahore.

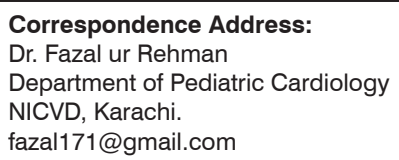

Correspondence Address:

Dr. Fazal ur Rehman

Department of Pediatric Cardiology

NICVD, Karachi.

fazal171@gmail.com

Article received on: Accepted for publication:
$12 / 04 / 2021$ $24 / 06 / 2021$ 
intraventricular hemorrhage (grade 4 and 5) are reduced with the use of prophylactic indomethacin if started within 12 hours of birth and no correlation with neurodevelopmental outcomes was observed. ${ }^{9}$ As not much work is conducted in Pakistan looking at possible prophylactic role of parenteral paracetamol on PDA closure, we planned this study to find out the effectiveness of prophylactic parenteral paracetamol to minimize rates of ductus patency among preterm infants.

\section{MATERIAL \& METHODS}

This case-control study was done at The Department of Pediatrics, "Sughra Shafi Medical Complex, Sahara Medical College, Narowal" Pakistan from March 2020 to February 2021. Approval from "Institutional Ethical Committee" was taken. Informed consent was sought from parents/guardians of all study participants. Sample size turned out to be 26 (13 in each group) considering Two-sided confidence level (1-alpha) 95\%, Power (\% chance of detecting) $80 \%$, ratio of Controls to Cases as 1, proportion of controls with exposure $71.3 \%$ and proportion of cases with exposure $15 \% .{ }^{8}$ A total of 70 neonates (35 cases and 35 controls) having gestational age less than or equal to 34 weeks were enrolled. Neonates having pulmonary artery atresia, aortic coarctation, genetic disease, persistent pulmonary hypertension, Apgar score at 5 minutes less than 5 or those with blood cord $\mathrm{pH}$ below 7.0 were not enrolled. Physical and clinical examination including heart and lung auscultation looking for murmurs along with 4-limb pulse oximetry and 4-limb blood pressure were measured following birth for the prediction of any possibility of ductus-dependent cardiac abnormality as in that case starting paracetamol and ductus closure might be disastrous.

All 35 cases were administered prophylactic parenteral paracetamol as $20 \mathrm{mg}$ per $\mathrm{kg}$ stat and $7.5 \mathrm{mg}$ per $\mathrm{kg} 6$ hourly for $1^{\text {st }} 3$ days of life while all controls were given no drugs. First dose of paracetamol was administered after 12 hours of birth as those first 12 hours were enough for the examination of neonates for any possibility of cyanosis, pathologic murmurs or any possible congenital heart disease or genetic disorders. Echocardiography was performed in all 70 neonates after first three post-natal days to identify PDA. In cases where PDA was found, ibuprofen was set as prompt treatment option. A special proforma was designed for recording all study data.

Data was analyzed using SPSS 26.0. Qualitative variables like gender presence of PDA and mortality were highlighted as frequency and percentages. Age, gestational age (weeks), body weight (grams) and duration of hospitalization were shown as mean and standard deviation. Qualitative variables were compared applying chi-square test while independent sample t-test was applied to compare quantitative variable between both study groups considering $\mathrm{p}$ value $<0.05$ as significant.

\section{RESULTS}

In a total of 70 neonates, 37 (52.9\%) were male and $33(47.1 \%)$ female. Overall, mean gestational age was noted to be $32.1+1.47$ weeks while mean body weight was recorded to be $1424.6+229.7$ grams. Table-l is showing characteristics neonates between both study groups and no significant difference was found ( $p>0.05)$.

\begin{tabular}{|c|c|c|c|c|}
\hline \multirow{2}{*}{\multicolumn{2}{|c|}{ Characteristics }} & Cases $(n=35)$ & $\begin{array}{c}\text { Controls } \\
(n=35)\end{array}$ & \multirow{4}{*}{$\begin{array}{c}\text { P- Value } \\
0.8108\end{array}$} \\
\hline & & $\begin{array}{c}\text { Number (\%)/ } \\
\text { Mean+SD }\end{array}$ & $\begin{array}{c}\text { Number (\%)/ } \\
\text { Mean+SD }\end{array}$ & \\
\hline \multirow{2}{*}{ Gender } & Male & 18 (51.4\%) & 19 (54.3\%) & \\
\hline & Female & $17(48.6 \%)$ & $16(45.7 \%)$ & \\
\hline \multicolumn{2}{|c|}{$\begin{array}{l}\text { Gestational Age } \\
\text { (weeks) }\end{array}$} & $32.2+1.35$ & $32.0+1.68$ & 0.5848 \\
\hline \multicolumn{2}{|c|}{$\begin{array}{l}\text { Body Weight } \\
\text { (grams) }\end{array}$} & $\begin{array}{c}1432.8 \\
+ \\
228.4\end{array}$ & $\begin{array}{c}1414.1 \\
+ \\
234.2\end{array}$ & 0.7763 \\
\hline
\end{tabular}

Table-Il is showing frequency of PDA noted among both study groups. There were 6 neonates $(17.1 \%)$ among cases who were found to have PDA in comparison to $23(65.7 \%)$ in controls $(p<0.0001)$.

\begin{tabular}{|l|c|c|c|}
\hline PDA & Cases $(\mathbf{n = 3 5 )}$ & Controls $(\mathbf{n = 3 5 )}$ & P-Value \\
\hline Yes & $6(17.1 \%)$ & $23(65.7 \%)$ & \multirow{2}{*}{$<0.0001$} \\
\hline No & $29(82.9 \%)$ & $12(34.3 \%)$ & \\
\multicolumn{2}{|c|}{ Table-II. Distribution of Frequency of PDA. $(\mathbf{n = 7 0 )}$} \\
\hline
\end{tabular}


In terms of mortality, 4 (11.4\%) neonates died in case group in comparison to 7 (20.0\%) among controls $(p=3245)$. Table-III is showing comparison of mortality among neonates of both study groups.

\begin{tabular}{|l|c|c|c|}
\hline Mortality & $\begin{array}{c}\text { Cases } \\
(\mathbf{n = 3 5 )}\end{array}$ & $\begin{array}{c}\text { Controls } \\
(\mathbf{n = 3 5 )}\end{array}$ & P-Value \\
\hline Yes & $4(11.4 \%)$ & $7(20.0 \%)$ & 0.3245 \\
\hline No & $29(88.6 \%)$ & $12(80.0 \%)$ & \\
\hline \multicolumn{2}{|c|}{ Table-III. Mortality among Neonates of Both Study } \\
Groups. \\
(n=70)
\end{tabular}

In terms of duration of hospitalization, mean duration of hospitalization was recorded to be $20.52+8.2$ days in case group in comparison to $24.81+4.6$ days among controls $(p=0.0088)$.

\section{DISCUSSION}

Treatment aiming promotion of rapid ductal closure is vital but surgery has its own risk whereas medications like ibuprofen and indomethacin are considered to be the choice of treatment. Indomethacin and ibuprofen are prostaglandin (PG) inhibitors which are frequently utilized aiming PDA closure. ${ }^{10}$

Not many studies have been conducted on paracetamol to measure its effectiveness regarding PDA closure while some have got inconclusive results. ${ }^{11-13}$ A trial evaluating prophylactic indomethacin and ibuprofen regarding PDA closure found that both drugs were effective but progression to renal failure and pulmonary hypertension were the reasons that the study was stopped. ${ }^{14}$ Hammerman et al revealed 5 cases having 26-32 weeks of gestation and 3 to 35 post-natal days administered oral paracetamol as ibuprofen was contraindicated or incapable regarding PDA closure. All those 5 cases achieved satisfactory outcomes regarding PDA closure with the utilization of paracetamol. ${ }^{15}$ In the present study $17.1 \%$ neonates who were administered paracetamol were found to have PDA in comparison to $65.7 \%$ who did not have prophylactic paracetamol $(p<0.0001)$. Some studies have found paracetamol to be effective alternative option aiming PDA closure among neonates who have contraindications for the use of indomethacin or ibuprofen or even those who do not achieve success with those two treatment options. ${ }^{16-18}$ Paracetamol is thought to work on PG synthetase in the peroxidase receptor of the enzyme that boosts paracetamol mediated inhibition at decreased local peroxide concentration which immediately inhibits PG synthase activity. Activation of peroxidase is done when peroxide concentration is ten times less than cyclooxygenase. This difference might be responsible for peroxidase inhibition to be fully effective in case of low cyclooxygenase inhibitory activity. ${ }^{19,20}$

Terrin et al in a clinical trial evaluating eight preterm neonates coercively receiving paracetamol due to contraindication of most frequently used drugs noted that $75 \%$ of the neonates had resolution of PDA without any adverse events. ${ }^{21}$ Other researchers in a case-control study also found paracetamol to be significantly effective in reducing PDA incidence. ${ }^{6}$ A recent systemic review stated paracetamol to be effective for PDA closure while it had fewer adverse events in comparison to ibuprofen. Paracetamol was found to have less duration required for PDA closure while there were less number of patients with gastrointestinal bleeding and hyperbilirubinemia. ${ }^{22}$

Our study had some limitations as well. This was a single center study with comparatively small sample size so findings of this study cannot be generalized. Further randomized controlled trials comparing paracetamol with other popular options considered for PDA closure like indomethacin and ibuprofen should be conducted to compare the results of these drugs. We could not record mean ventilator time or mean cardiac fractioning shortening among neonates in the present study.

\section{CONCLUSION}

Prophylactic parenteral paracetamol was found to prevent ductus patency among preterm neonates. In comparison to controls, duration of hospital stay was significantly short among neonates who were administered prophylactic parenteral paracetamol.

Copyright $(24$ June, 2021. 


\section{REFERENCES}

1. Dzialowski EM. Comparative physiology of the ductus arteriosus among vertebrates. Semin Perinatol. 2018; 42(4):203-211.

2. Conrad C, Newberry D. Understanding the pathophysiology, implications, and treatment options of patent ductus arteriosus in the neonatal population. Adv Neonatal Care. 2019; 19(3):179-187.

3. Prescott S, Keim-Malpass J. Patent ductus arteriosus in the preterm infant: Diagnostic and treatment options. Adv Neonatal Care. 2017; 17(1):10-18.

4. Fowlie PW, Davis PG. Prophylactic intravenous indomethacin for preventing mortality and morbidity in preterm infants. Cochrane Database Syst Rev 2012; 3:CD000174.

5. Ohlsson A, Walia R, Shah SS. Ibuprofen for the treatment of patent ductus arteriosus in preterm or low birth weight (or both) infants. Cochrane Database Syst Rev 2018; 9:CD003481.

6. Aikio O, Harkin P, Saarela T, Hallman M. Early paracetamol treatment associated with lowered risk of persistent ductus arteriosus in very preterm infants. J Matern Fetal Neonatal Med. 2014; 27(12):1252-6.

7. Wilson-Smith EM, Morton NS. Survey of I.V. paracetamol (acetaminophen) use in neonates and infants under 1 year of age by UK anesthetists. Paediatr Anaesth. 2009; 19(4):329-37.

8. Bagheri MM, Bahman-Bijari B, Torabi-Nejad MH, Niknafs P, Mousavi H, Sabzevari F, et al. Is prophylactic parenteral paracetamol effective to diminish incidence of PDA in preterm neonates? A randomized trial. Iran J Pediatr. 2018; 28:10-3.

9. Martin RJ, Fanaroff AA, Walsh MC. Neonatal perinatal medicine. 10th ed. USA: William E. Benitz; 2015. p. 1225-6. 1242-4.

10. Rostas SE, Mc Pherson CC. Pharmacotherapy for patent ductus arteriosus: Current options and outstanding questions. Curr Pediatr Rev. 2016; 12:110-9.

11. Yang $B$, Gao $X$, Ren $Y$, Wang $Y$, Zhang Q. Oral paracetamol vs. oral ibuprofen in the treatment of symptomatic patent ductus arteriosus in premature infants: A randomized controlled trial. Exp Ther Med. 2016; 12:2531-6.
12. El-Mashad A, El-Mahdy H, El Amrousy D, Elgendy M, ElMashad AE-R. Comparative study of the efficacy and safety of paracetamol, ibuprofen, and indomethacin in closure of patent ductus arteriosus in preterm neonates. Eur J Pediatr. 2017; 176:233-40.

13. Al-LawamaM, Alammori I, Abdelghani T, Badran E. Oral paracetamol versus oral ibuprofen for treatment of patent ductus arteriosus. J Int Med Res. 2018; 46:8118.

14. Gournay V, Roze JC, Kuster A, Daoud P, Cambonie $G$, Hascoet JM, et al. Prophylactic ibuprofen versus placebo in very premature infants: A randomised, double-blind, placebo-controlled trial. Lancet. 2004; 364(9449):1939-44.

15. Hammerman C, Bin-Nun A, Markovitch E, Schimmel MS, Kaplan M, Fink D. Ductal closure with paracetamol: A surprising new approach to patent ductus arteriosus treatment. Pediatrics. 2011; 128(6):e1618-21.

16. Dani C, Poggi C, Cianchi I, Corsini I, Vangi V, Pratesi $S$. Effect on cerebral oxygenation of paracetamol for patent ductus arteriosus in preterm infants. Eur $\mathrm{J}$ Pediatr. 2018; 177:533-9.

17. Le J, Gales MA, Gales BJ. Acetaminophen for patent ductus arteriosus. Annals of Pharmacotherapy. 2015 Feb; 49(2):241-6.

18. Allegaert K, Anderson B, Simons S, Van Overmeire B. Paracetamol to induce ductus arteriosus closure: Is it valid?. Archives of disease in childhood. 2013 Jun 1; 98(6):462-6.

19. Green K, Drvota V, Vesterqvist O. Pronounced reduction of in vivo prostacyclin synthesis in humans by paracetamol. Prostaglandins. 1989; 37:311-5.

20. Kulmacz RJ, Wang LH. Comparison of hydroperoxide initiator requirements for the cyclooxygenase activities of prostaglandin $\mathrm{H}$ synthase-1 and-2. J Biol Chem. 1995; 270:24019-23.

21. Terrin G, Conte F, Scipione A, Bacchio E, Conti MG, Ferro $R$, et al. Efficacy of paracetamol for the treatment of patent ductus arteriosus in preterm neonates. Ital $\mathrm{J}$ Pediatr. 2014; 40(1):21.

22. Xiao Y, Liu H, Hu R, You Q, Zeng M, Jiang X. Efficacy and safety of paracetamol for patent ductus arteriosus closure in preterm infants: An updated systematic review and meta-analysis. Front Pediatr. 2020; 7:568. 


\begin{tabular}{|c|l|l|l|}
\hline \multicolumn{3}{|c}{ AUTHORSHIP AND CONTRIBUTION DECLARATION } \\
\hline No. & \multicolumn{1}{|c|}{ Author(s) Full Name } & \multicolumn{1}{|c|}{ Contribution to the paper } & Author(s) Signature \\
\hline 1 & Bushra Madni & Introduction, Proof reading. & \\
\hline 2 & Muhammad Imran & Literature review, Methodology. & \\
\hline 3 & Muhammad Naveed & Data collection, Discussion. & \\
\hline 4 & Fazal ur Rehman & Literature review, Data analysis. \\
\hline 5 & Khurram Shahnawaz & $\begin{array}{l}\text { Idea, Data collection, Final } \\
\text { approval. } \\
\text { Drafting, References. }\end{array}$ \\
\hline
\end{tabular}

